\title{
160. Sex Reversal in the Serranid Fish, Sacura margaritacea. I
}

\section{Sex Characters and Changes in Gonads during Reversal}

\author{
By Yô K。OKadA, M.J。A。 \\ (Comm. Oct. 12, 1965)
}

The serranid fish first named Anthias margaritaceus by Hilgendorf (1879) is elongate oval in shape, measuring $10-13 \mathrm{~cm}$ in body length. They are bright red in general coloration, although the basal region of the second dorsal fin and circumoral portion are tinted blue. Along the sides of the trunk, milky white spots are scattered irregularly in two longitudinal rows. The third spine of the first dorsal fin is produced into a long filament with a black tip. The posterior end of the abdominal fin is also colored black (Fig. 1A).

It has long been known that smaller yellowish specimens, 6-10 cm long, occur together with the above mentioned bright red forms in the same localities. The yellowisn fish are devoid of white spots along the sides of the trunk, bearing a large black patch on the posterior part of the first dorsal fin (Fig. 1D). Döderlein (1883) distinguished the yellow fish from the red ones, naming

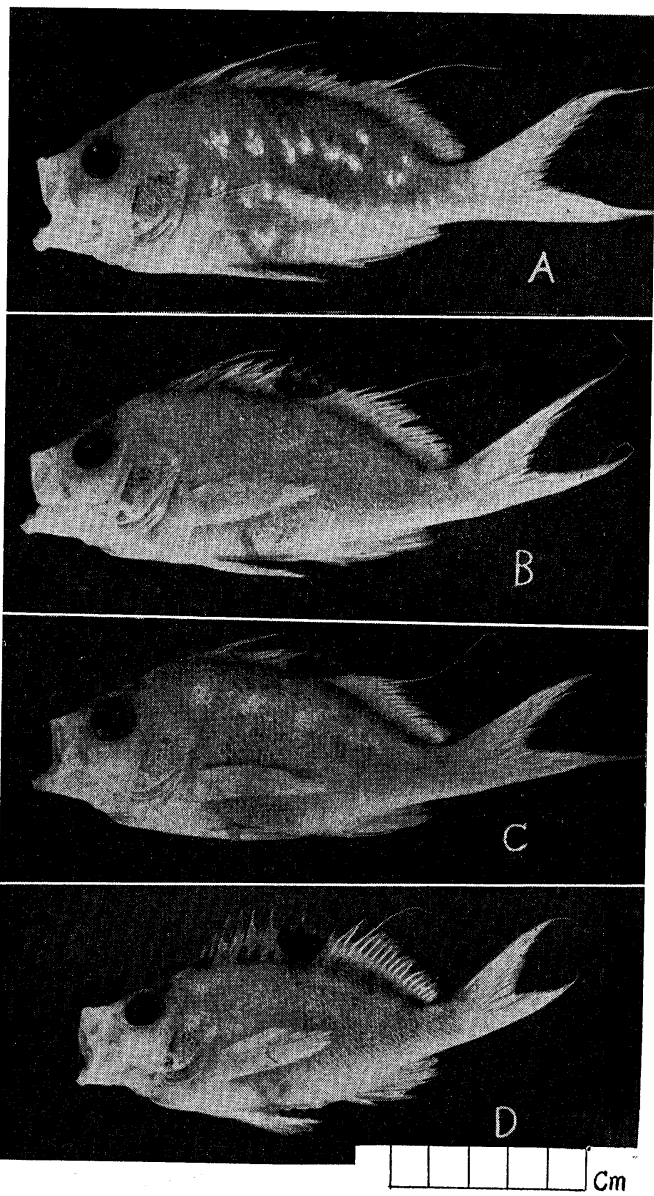

Fig. 1. Sacura margaritacea, A, male; B-C, two types of intermadiate form; $D$, female. In $B$, the black patch on the first dorsal fin is fading but white spots have not yet appeared on the side of the trunk. In $\mathrm{C}$, the first dorsal fin has a distinct black patch and white spots are appearing on the side of the body. $\times 2 / 5$ 
the former Anthias pulcher. Since Jordan and Thomson (1914) later transferred these fishes to the genus Sacura, the scientific names of the two fishes are Sacura margaritacea and Sacura pulcher, respectively.

More recently, Kuroda (1931a) found that, between the red and yellowish specimens, there were forms intermediate in coloration and that, of 24 specimens collected at Shige near Numazu, Shizuoka Prefecture, all of 9 bright red ones referable to $S$. margaritacea were males, while 15 yellowish ones referable to S. pulcher were invariably females. On the basis of this finding, Kuroda (1931b) postulated that red and yellowish specimens might be males and females of the same species.

A question arises here as to whether female $S$. pulcher would transform into male $S$ 。 margaritacea during development, as in the case of the labrid fish, Halichoeres poecilopterus, reported previously (Okada, 1962). The answer in the affirmative was given by Reinboth (1963), on the basis of his histological studies of the gonads from 48 of 86 specimens collected at Shige (vide supra) in 1961. According to him, all of 16 fish less than $94 \mathrm{~mm}$ in length were females, while 46 over $105 \mathrm{~mm}$ long were males. Of 24 specimens measuring 95-104 mm, 7 were intermediate between the two in the state of gonads.

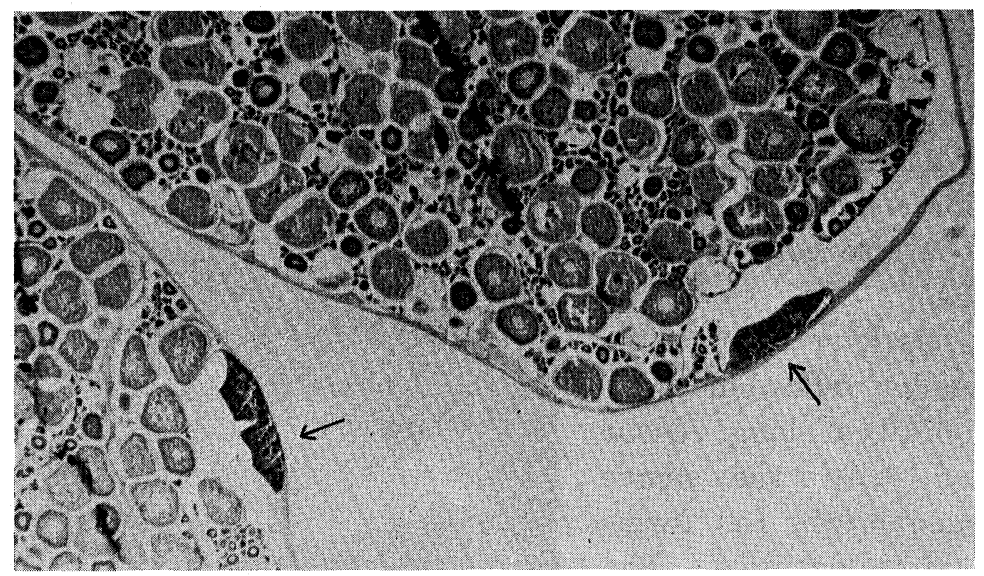

Fig. 2. Gonad of female with testicular primordia (indicated by arrows). $\times 15$

In these specimens, testicular primordia which were precociously found in the ovaries of typical females of smaller sizes (Fig。2) had undergone development to varying degrees, while ovarian lamellae containing oocytes always exhibited signs of degeneration。 Reinboth described as follows: "In jedem Falle gehen ein fortschreitender Zerfall der Oocyten und eine Grössenzunehme des Testis, der schliesslich des Ovariallumen ausfüllt, einander parallel". 


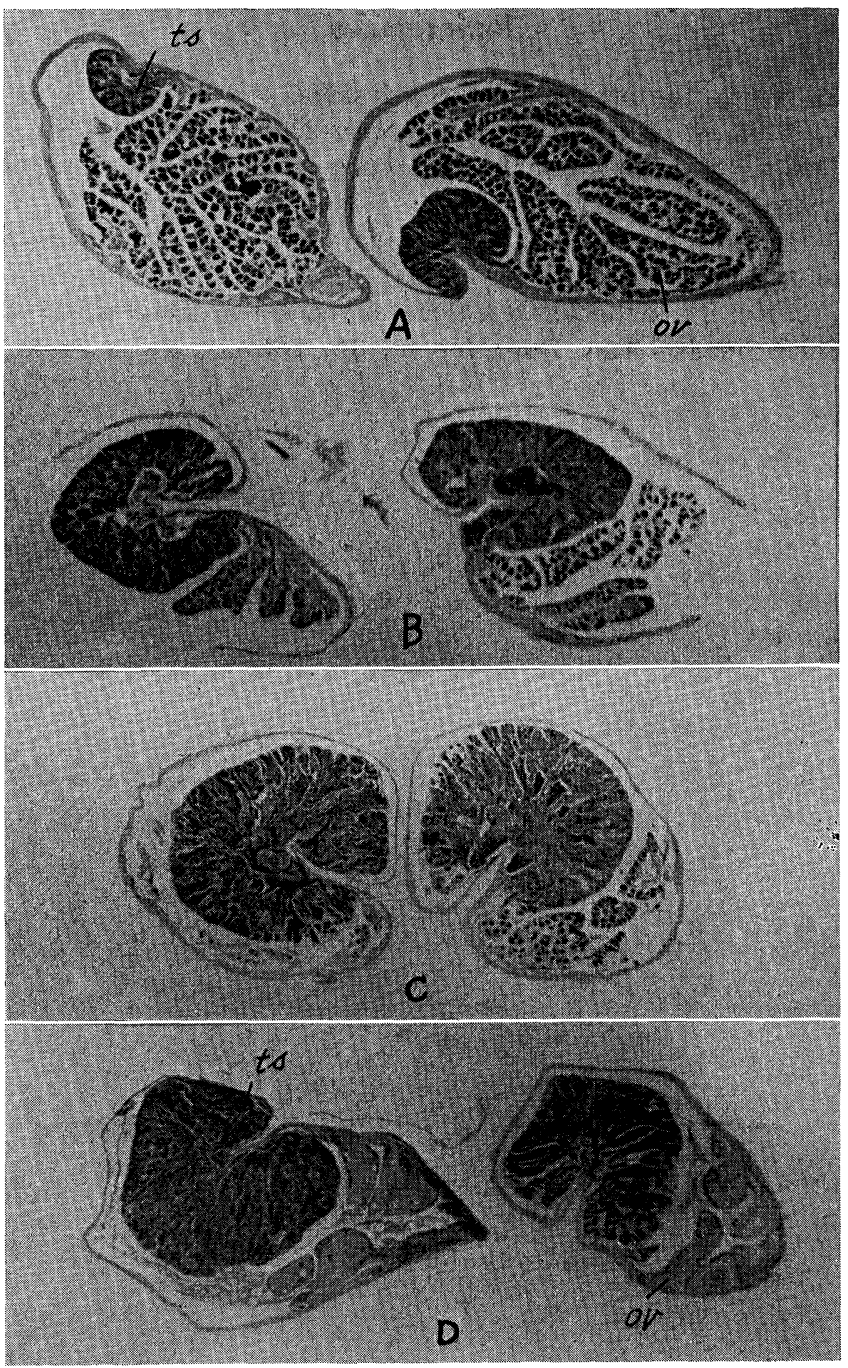

Fig. 3. Gonads during sex reversal. A-C, from specimens collected in May-June; $\mathrm{D}$, from specimen collected in October. Ov, ovarian lamellae; $t$, developing testis. $\times 16$

However, his studies were solely based on materials collected in the middle of June, 1961, and accordingly, although the final conclusions might probably be correct, processes of sex inversion were not thoroughly understood. It is the object of the present paper to provide further information in this respect. A series of photomicrographs (Fig. 3) of sections of gonads from intermediate forms will clearly show how the developing testis fills up the ovarian cavity parallel with the degeneration of ovarian lamellae in the course of sex reversal in Sacura margaritacea. 


\section{References}

Katayama, M. (1960): Fauna Japonica Serranidae.

(Sacura margaritacea (Hilgendorf) p. 149, pls. 20, 77) Biogeogr. Soc. Jap., Tokyo. Kuroda, N. (1931): Male and female of Sakura-dai and their scientific names (in Japanese). Zool. Mag., 43, 627.

Okada, Y. K. (1962): Sex reversal in the Japanese wrasse Halichoeres poecilopterus. Proc. Japan Acad., 38, 508.

Reinboth, R. (1963): Naturlicher Geschlechteswechsel bei Sacura margaritacea (Hilgendorf) (Serranidae). Ann. Zool. Japon., 36, 173. 